\title{
An Empirical Study on the Influence of PBL Teaching Model on the Critical Thinking Ability of Non-English Majors
}

\author{
Jinzhu Zhang \\ School of Foreign Languages, Tianjin Polytechnic University, Tianjin, China \\ Hongquan Lin \\ Personnel Section, Tianjin Polytechnic University, Tianjin, China
}

\begin{abstract}
This study combines the PBL teaching model based on cooperative learning autonomous learning and inquiry learning with the intensive reading course of college English with the aim to test whether this model is conducive to promoting the critical thinking ability of students. Ability of second language acquisition (L2) is measured by language test and questionnaire survey among 95 subjects. The results show that the teaching model of PBL has a positive effect on improving students' critical thinking ability and second language acquisition ability.
\end{abstract}

Index Terms — critical thinking ability; problem-based learning; language ability

\section{INTRODUCTION}

\section{A. Critical Thinking}

Facione (1992) defines critical thinking (CT) as an ability "to be purposeful, self-regulatory judgment which results in interpretation, analysis, evaluation, and inference, as well as explanation of the evidential, conceptual, methodological, criteriological, or contextual considerations upon which that judgment is based." The cultivation of critical thinking ability is not only the foundation of information processing ability and autonomous learning ability, but also the precondition of innovative thinking. Therefore, presently, the cultivation of students' critical thinking ability has become an important goal of teaching.

\section{B. PBL Teaching Model}

PBL (Problem-Based Learning) is a teaching strategy, originated from School of Medicine at McMaster University in Canada in the middle of 1960s, was firstly intended to improve the teaching quality by replacing the traditional teaching model. Since then, it has been widely extended to the fields of engineering, construction, business education and social work. Up till now, there is still no widely accepted definition of PBL teaching strategy, but all researchers agree that PBL is a student-based teaching conception, which provides real problem situations and allows students to solve problems and construct knowledge in a learning environment that is both autonomous and cooperative. Nelson (2008) puts forward a more comprehensive definition: PBL is a teaching strategy, which begins with a question to students, asks students to work in groups to solve a complex and chaotic problem that may be encountered in real society; the process of problem solving allows students to actively participate in the analysis of the problems, to review the knowledge they have acquired, and to identify the relevant facts, finally new knowledge is constructed On the basis of learning activities above. Students collectively decide which problems need to be discussed jointly by the group, and which problems can be carried out by the individuals. At the same time, they may design plans to solve the problems. In terms of cultivation of critical thinking, Almost all the studies have shown that the teaching of critical thinking should be based on problem-solving strategies, and the ultimate purpose of problem-solving is considered to be the core of PBL learning model. In PBL teaching model, learners can produce critical thinking and creative thinking by coping with various difficult problems. ZhiYongbi (2014) defines PBL teaching model as an excellent container for promoting thinking.

\section{Effects of PBL Teaching Model on SLA}

First of all, the PBL teaching model, which is characterized by interaction, provides students and teachers with a wide range of information exchange platforms, where the meaning negotiation and formal negotiation between students and learners with stronger language proficiency is carried out in different forms of interaction in classroom learning. This kind of effective negotiation is undoubtedly beneficial to promote the development of second language acquisition (Zhao, 2015), secondly, The PBL teaching model based on cooperative learning can effectively reduce the anxiety of students and provide a safer and more favorable psychological environment for foreign language learning. Furthermore, 
The problem-based PBL teaching model enables students to transfer from passive learning to a positive discovery learning model, thus enhancing their learning interests and motivation. Therefore, PBL teaching model provides a new platform for the improvement of second language acquisition ability.

\section{Literature Review}

In the past 10 years, the research on critical thinking has been paid more attention by domestic researchers. There have been numerous related works in the field of second language acquisition and educational psychology. on the CNKI(Chinese National knowledge Internet), the biggest and the most popular research and paper database in China, The author searches the papers with the key words "critical thinking ability/speculative ability" and "English Teaching", 370 papers are found, with 79 in key journals and 58 theses for mater' degree, which indicates that the cultivation of critical thinking with the aid of foreign language teaching has been paid more and more attention to in recent years, especially in the teaching of college English reading and writing. This study attempts to explore the effects of PBL on critical thinking and second language acquisition by constructing a curriculum model of combining PBL teaching model with intensive reading course.

\section{RESEARCH METHODOLOGY}

\section{A. Research Questions}

1) Is the PBL teaching model helpful to improve the critical thinking ability of learners?

2) Is PBL teaching model helpful to improve learners' language competence?

\section{B. Subjects}

This study was conducted in two English classes randomly selected from Tianjin Polytechnic University in 2017, one of class with 48 students was used as the experimental group; The other class with 47, was taken as the control group, each class had an average age of 18.2 and 18.5 respectively. And the average scores of college entrance examination English were 112.6 and 110.9 respectively. The two groups had the same teaching hours for 16 teaching weeks, offering the same college English courses, enjoying the same learning and living environment in the teaching experiment. The experimental group adopted the PBL teaching model, the control group adopted the traditional teaching model. As a whole, there was no significant difference in language proficiency between the two groups, and the experimental environment was similar. the basic conditions to carry out the comparative teaching experimental research were fully equipped.

\section{RESEARCH PROCEDURES}

\section{A. Preparation Stage}

The preparation process of the experiment included grouping, role assignment, group leader selection,and establishment of assessment system

Grouping in the experimental group was in accordance with the voluntary principle, and a harmonious community was established to provide a good basis of cooperative learning for members in the group. Members in each group were assigned to six characters respectively: data searchers, material analyzers, translators, proofreaders of the translated materials, multimedia producers, team spokesmen and leaders who were responsible for the overall planning of tasks. They were encouraged to choose the roles based on their strengths, and to take turns to assume different roles.

The success of the PBL model depends largely on whether the students are adequately prepared to take on new roles, such as being a curious knowledge seeker and a cooperator of the tasks (Boud, 1997). therefore, in order to ensure the smooth progress of the experiment, four weeks before the experiment, Students participating in the PBL model were trained to become fully familiar and gradually (see Table 1) adapt to their roles and responsibilities in the PBL model, where teachers are constantly reinforcing the concept of cooperation and organizing students to reflect and evaluate the learning activities. 
TABLE I.

THE Process Of DEVELOPING A COOPERATIVE MODEL

\begin{tabular}{|c|c|c|c|}
\hline Stages & Measures & Efficiency & Evaluation strategy \\
\hline Beginning & $\begin{array}{l}\text { In order to cultivate students' } \\
\text { cooperative mind, some simple } \\
\text { classroom cooperative tasks, } \\
\text { such as mutual evaluation of } \\
\text { composition, and cooperative } \\
\text { dictation, are assigned to } \\
\text { students at the beginning. }\end{array}$ & $\begin{array}{l}\text { Reinforcement of Group leader's sense of } \\
\text { responsibility: } \\
\text { Organization of group activities; } \\
\text { supervision of other members to learn and } \\
\text { give help to other students; shift from self- } \\
\text { centered learning model to focus on group } \\
\text { members and group honor; }\end{array}$ & $\begin{array}{l}\text { Formative evaluation of students' group } \\
\text { activities in class, emphasis on the basis of } \\
\text { group activities, and leading students into the } \\
\text { track of cooperative learning gradually. }\end{array}$ \\
\hline Forming & $\begin{array}{l}\text { Strengthening self-evaluation } \\
\text { in the implementation of PBL } \\
\text { model }\end{array}$ & $\begin{array}{l}\text { Cooperation on track: } \\
\text { with the development of the PBL model, } \\
\text { problems arise and continue to be solved. } \\
\text { The team members constantly understand } \\
\text { and adapt to each other's characteristics in } \\
\text { the process of cooperation. The team } \\
\text { leaders will also develop a mechanism for } \\
\text { team cooperation according to the } \\
\text { characteristics of the team members, avoid } \\
\text { conflicts effectively and maximize } \\
\text { cooperation }\end{array}$ & $\begin{array}{l}\text { Reflection from group leaders: } \\
\text { When, where and how to start a panel } \\
\text { discussion? How do you describe the } \\
\text { characteristics of your team? } \\
\text { How do you handle conflicts in cooperation? } \\
\text { How to strengthen group cohesion? } \\
\text { Team reflection program: How do you } \\
\text { benefit from PBL model? How do you break } \\
\text { through yourself in this new model? What } \\
\text { will you do to make sure the team can work } \\
\text { together? }\end{array}$ \\
\hline
\end{tabular}

After a period of training, students have gradually developed the cooperation model as is shown in figure 1:

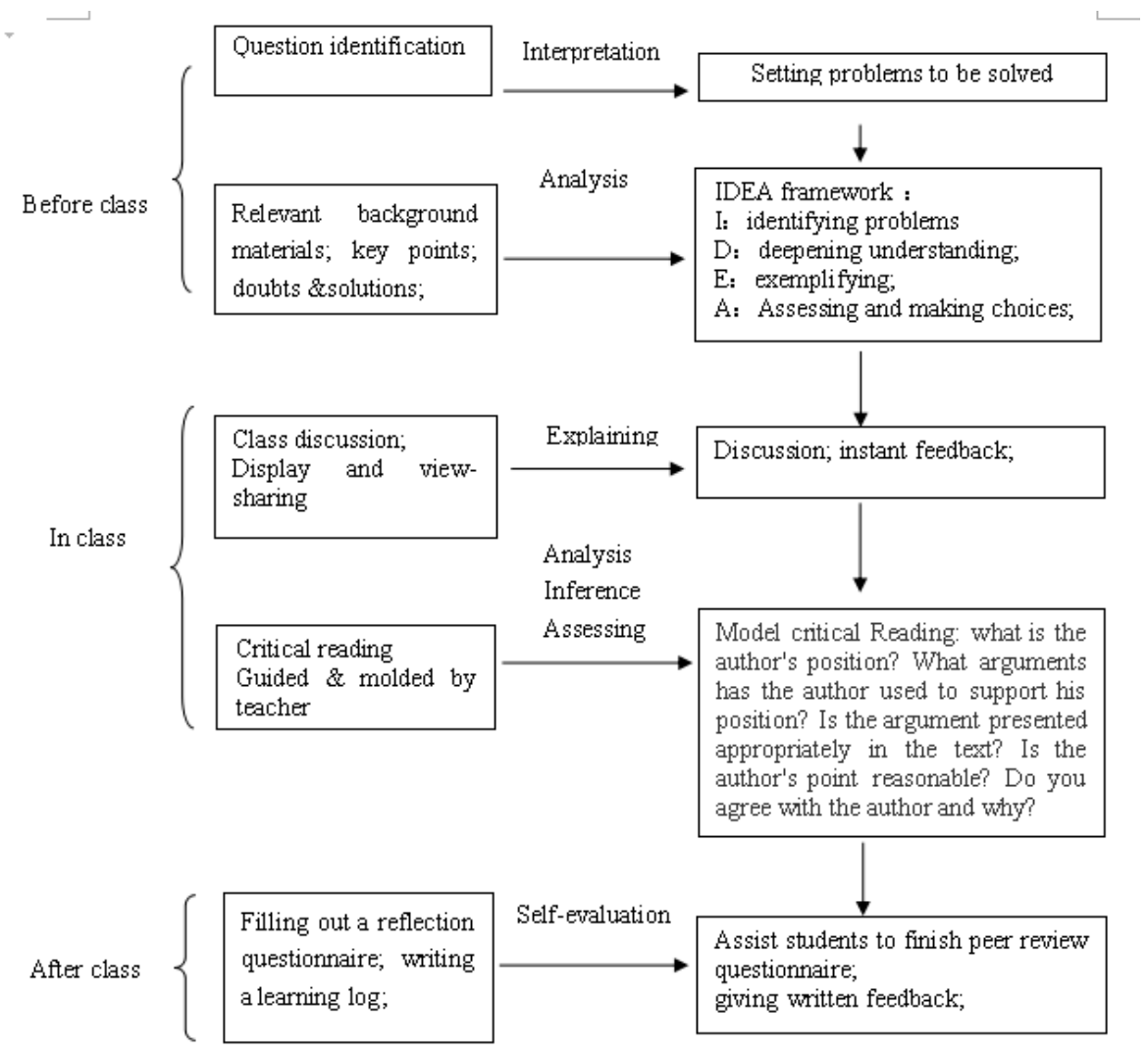

Figure 1: The cooperation model of students

\section{B. Implementation of the Research}

The PBL teaching model is officially launched. Teachers create Domino Effects to stimulate students' researchoriented learning actions, provide resources and methods to solve problems, promote students to use critical thinking to discover and master new knowledge through evaluation and assessment, and develop thinking ability by solving practical problems. PBL teaching process involves three sectors: group activities before class, cooperative learning in class, reflection and evaluation after class (see figure 2). 


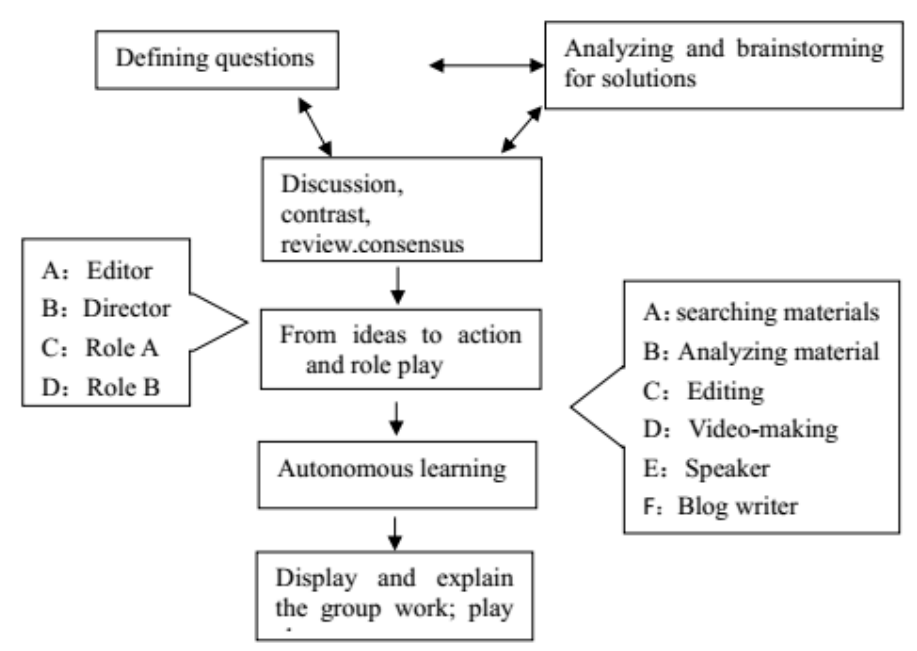

Figure 2. The process of experiments

In the phase of group pre-class activities, the teacher firstly sets up a real-life problem for students that is relevant to the topic of the unit they are going to learn, but the problems are unstructured without a fixed solution. They are intended to arouse students' interests and to form a multifaceted solution through discussion. Besides, students are provided with a framework for measuring critical thinking skills to guide and test whether or not they have applied critical thinking to the problem-solving (Facione, 2013). When students are faced with complex problems, they can use the skills of classification, identification, clarification, differentiation, interpretation and other critical thinking to sort out the context of the problem in a relaxed and orderly manner, consider the various restrictive factors comprehensively and finally find the best solution by measuring all kinds of solutions.

In class activities, teachers are supposed to provide students with the time and stage to display the results of group activities in the classroom. At the same time, teachers should provide targeted and individualized feedback to each group of students after students' report. In addition to measuring the fluency of the students' language expression, Teachers can adopt the comprehensive evaluation of critical thinking skills and temperament of students in the process of solving problems. It is suggested that teachers adopt the criteria provided by Wen Qiufang, etc in the theoretical models of critical thinking ability. Besides offering time and stage for students to display, In order to improve students' critical reading ability and the effect of extra-curricular reading, teachers need to demonstrate the process of critical reading to students in the classroom based on textbooks. By asking questions step by step, the teacher leads students to understand the theme of the article, analyze and evaluate the logical thinking of the author, and then help students to gradually understand and master the concept and skills of critical thinking in the interpretation of an article.

It is usually possible to use the question strategy shown in figure 2 (Payne, 2006) to ask students to conduct a selfevaluation in the reflection and evaluation stage after class to test whether they have applied critical thinking skills to the process of problem-solving or not. Meanwhile, teachers should also evaluate whether students have displayed the temperament of critical thinking and ask students what problems have been encountered in the process of solving problems and acquiring new knowledge, whether they have actively faced and sought solutions to problems by building an environment of questioning and inquiring. Students can use logical ideas and reflect on the whole process of thinking, they are becoming more and more willing to reflect and modify their thinking.

\section{ResEARCh ToOls \& Data Collection}

\section{A. Research Tools}

The present study employs both quantitative and qualitative approaches. The quantitative approach is designed to investigate the critical thinking skills and tendencies of students and to check whether there are significant differences in their second language acquisition abilities before and after the experiment. To investigate the attitudes of teachers and students towards the PBL teaching model, the main research tools are questionnaires and language tests. The test designed is based on the National College English Test 4 of 2016 (CET-4), covering the examination of listening, reading,writing and translating. The questionnaire includes questions on critical thinking skills and students' disposition. The questionnaire employs the professor Wen Qiufang's adapted version based on the California Critical Thinking Disposition Inventory(CCTDI) (Facione, 1992), which Includes eight dimensions: analysis, truth-seeking, curiosity, self-confidence, tenacity, openness, maturity, and fairness, were reduced from 75 to 54 items, and the dimensions of fairness are tested. The total reliability of the questionnaire is 0.810 , and the reliability of each dimension is between 0.51 (justice) and 0.73 (tenacity), so the reliability of the questionnaire is much higher than the acceptable value of 0.4 .

The questionnaire of critical thinking ability, which is based on critical reading skills, adopts the form of the Richter scale, which consists of 28 options and 6 dimensions, and is tested by SPSS 17.7 statistical software for its reliability 
and validity. The total reliability of the scale was 0.913 , and the reliability of each dimension was between 0.496 (analysis) and 0.791 (self-regulation). The results of KMO and Bartlette's tests showed that KMO $=0.864>0.5$, which indicates that the validity of the questionnaire is good.

\section{B. Data Collection}

The experiment includes pre-test and post-test. Two groups of students are tested by language tests and questionnaires before the beginning of PBL teaching model. By the end of PBL teaching model, two groups of students are also given language tests and questionnaires as the basis of the post-test. 180 questionnaires were sent out by the teacher in the beginning and the final period. The recovery rate is $100 \%$, and then the language test data and the questionnaire data were entered into SPSS 17.7 to analyze. An interview for students is also carried out.

\section{RESUlTS AND DisCUSSION}

\section{A. Analysis on the Results of Questionnaire of the Critical Thinking Disposition}

In order to compare whether there were significant differences in the use of critical thinking tendency and critical skills between the two groups after one semester's training and study, we use an independent sample T test in pre-test and post-test. At the same time, in order to verify that each group of students have made significant differences in their own learning, paired samples are used to test the results of T test, such as Table 2 and Table 3.

TABLE II.

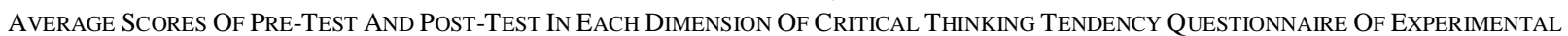

\begin{tabular}{|l|l|l|l|}
\hline Items & Average scores of pre-test & Average scores of post-test & P values \\
\hline Analysis & 38.62 & 40.13 & .002 \\
\hline Curiosity & 45.13 & 45.60 & .411 \\
\hline Tenacity & 34.56 & 35.17 & .319 \\
\hline Confidence & 38.82 & 41.13 & .008 \\
\hline Truth & 37.46 & 40.07 & .028 \\
\hline Maturity & 38.57 & 40.33 & .011 \\
\hline Openness & 39.89 & 42.07 & .024 \\
\hline Justice & 38.65 & 43.64 & .000 \\
\hline
\end{tabular}

TABLE III.

INDEPENDENT SAMPLE T-TEST OF PRE-TEST AND POST-TEST RESUlts IN CRITICAL THINKING TENDENCY QUESTIONNAIRE

\begin{tabular}{|l|l|l|l|l|}
\hline Items & Pre-test & Post-test \\
\hline & T values & P values & T values & P values \\
\hline Analysis & .038 & .970 & 2.641 & .010 \\
\hline Curiosity & 1.104 & .272 & 1.957 & .053 \\
\hline Tenacity & .947 & .346 & 1.676 & .096 \\
\hline Confidence & .362 & .718 & 2.425 & .017 \\
\hline Truth-seeking & .667 & .507 & 2.283 & .024 \\
\hline Maturity & .149 & .882 & 2.150 & .034 \\
\hline Openness & 1.079 & .284 & 2.187 & .031 \\
\hline Justice & 1.162 & .248 & 4.341 & .000 \\
\hline
\end{tabular}

In the questionnaire of critical thinking, the scores for each dimension ranged from 10 to 60,40 or more is with a positive tendency; 30 or below is with a negative tendency; scores between 31 and 39 is with a swaying tendency. as it can be seen from Table 2, before participating in the PBL teaching experiment, the students in the experimental group have shown a positive tendency of curiosity. Although the other dimensions are not negative, they still did not reach the ideal state of positive tendency, among which, the tenacity was the least ideal.

in Table 3. The $\mathrm{P}$ values of critical thinking tendency in each dimension are $0.970,0.272,0.346,0.718,0.507,0.882$, $0.284,0.248,0.05$ respectively, which indicates that there is no significant difference in critical thinking tendency between the experimental group and the control group before and after the experiment. The $\mathrm{P}$ values of analysis, confidence, truth-seeking, maturity, openness and justice are 0.010, 0.017, 0.024, 0.024, 0.034, 0.031, $0.000, \mathrm{p}<0 \mathrm{05}$ respectively, which indicates that there are significant differences between the two groups in the dimensions above. but in dimensions of curiosity and tenacity, there are significant differences between the two groups. $\mathrm{P}$ values are 0.053 and 0.096 respectively, indicating that there is no significant difference between the two groups in the two dimensions. The results show that PBL teaching methods have a positive effect on the development of critical thinking of students. Compared with traditional teaching, PBL teaching model is more helpful to promote students' ability to solve problems and develop critical thinking.

Burris, Garton (2007) did not find significant changes in critical thinking in the subjects in his experiment. He attributed it to the short period of the experiment, which lasted only two weeks compared to 10-16 weeks in previous studies. The experiment must have a long enough period to adapt students to the new teaching and learning model to verify the effectiveness of PBL. Tiwariet al (2012) conducted three stages of experiments with Hong Kong students, China. The results showed that there were significant differences in the dimension of truth-seeking, analysis and self- 
confidence in the first stage of the study. However, in the third stage of the experiment, there is significant difference in the dimension of tenacity. Therefore, in this experiment, the tenacity tendency of the experimental group needs a longer experimental period to make a significant difference. Besides, there is no significant change in the dimension of curiosity. But before the experiment, the students have shown a strong positive tendency, so we believe that it is difficult to change significantly when the subjects reach a positive tendency.

\section{B. Analysis on the Results of Questionnaires about Critical Thinking Ability}

TABLE IV.

INDEPENDENT SAMPLE T-TEST OF PRE-TEST AND POST-TEST RESUlTS IN CRITICAL THINKING SKILLS QUESTIONNAIRE BETwEEN TwO GROUPS

\begin{tabular}{|c|c|c|c|c|}
\hline Items & \multicolumn{2}{|l|}{ Pre-test } & \multicolumn{2}{|l|}{ Post-test } \\
\hline & $\mathrm{T}$ values & $\mathrm{P}$ values & $\mathrm{T}$ values & $\mathrm{P}$ values \\
\hline Interpretation & .723 & .457 & 2.140 & .038 \\
\hline Analysis & .037 & .967 & 2.150 & .034 \\
\hline Evaluation & .074 & .947 & 2.666 & .009 \\
\hline Reasoning & 1.420 & .133 & .425 & .671 \\
\hline Explanation & .324 & .436 & 2.592 & .011 \\
\hline Self regulation & .165 & .566 & .652 & .516 \\
\hline
\end{tabular}

TABLE V.

PAIRED SAMPLE T-TEST OF PRE-TEST AND POST-TEST IN CRITICAL THINKING ABILITy QuestionNAIRES BETWEEN Two GROUPS

\begin{tabular}{|l|l|l|l|l|}
\hline Items & Experimental group & Control group \\
\hline & T values & P values & T values & P values \\
\hline Interpretation & 8.504 & .020 & .580 & .566 \\
\hline Analysis & 9.356 & .002 & .425 & .671 \\
\hline Evaluation & 9.478 & .000 & .652 & .516 \\
\hline Reasoning & 4.853 & .321 & .822 & .312 \\
\hline Explanation & 7.584 & .026 & .764 & .436 \\
\hline Self regulation & 3.760 & .483 & .712 & .467 \\
\hline
\end{tabular}

In the $\mathrm{T}$ test of independent samples of pre-test, The $\mathrm{P}$ values of the two groups of students in the dimensions of interpretation, analysis, evaluation, reasoning, explanation and self-regulation are $0.457,0.967,0.947,0.133,0.436$, 0.566 respectively, $(\mathrm{p}>0.05)$, indicating that there is no significant difference between two groups of subjects in the dimensions above. In the post-test, the $\mathrm{P}$ values of each dimension were. 0.0380 .0340 .0090 .6710 .0110 .516 , which indicated that the two groups showed significant differences in interpretation analysis, evaluation and interpretation $(\mathrm{p}<0.05)$. However, there was no significant difference between the two groups in the dimension of reasoning and selfregulation $(\mathrm{p}>0.05)$. in the following paired sample T-test, The $\mathrm{P}$ values in each dimension of the experimental group are 0.0200 .00200 .00200 .0000 .0000 .3210 .0260 .483 respectively, which indicates that the students in experimental group have made a significant change in interpretation, analysis, evaluation and the use of explanation skills after one term of study $(\mathrm{p}<0.05)$. However, there is no significant change in the dimension of reasoning and self-regulation ( $\mathrm{p}>0.05$ ). The results of paired sample t-test show that the $\mathrm{P}$ value of each dimension is greater than 0.05 , indicating that the traditional teaching does not have a significant impact on students' critical thinking ability. in comparison, the PBL teaching model has provided students with abundant pre-class and after-class activities, which have offered students a wide range of space to develop and use their critical thinking ability through defining problems, analyzing materials, demonstrating programs, presenting results, self-evaluating and peer evaluating. The research result is very similar to the conclusion of Albanese Mitchell (2009) that the introduction of PBL teaching model has a significant effect on the improvement of students' meta-cognitive ability with manifestation in the improvement of students' ability to understand concepts and apply knowledge.

\section{Analysis of Language Test Results}

TABLE VI.

Two SETS OF INDEPENDENT SAMPLE T-TESTS IN LANGUAGE TESTING

\begin{tabular}{|l|l|l|l|l|l|l|l|}
\hline Pre-test of listening & 11.0000 & 2.18143 & 10.4667 & 2.01260 & 0.5333 & .984 & .329 \\
\hline Post-test of listening & 13.7000 & 2.84241 & 11.5667 & 2.22344 & 2.1333 & 3.238 & .002 \\
\hline Pre-test of reading & 26.3333 & 3.15500 & 25.6000 & 3.27225 & 0.7333 & 1.018 & .313 \\
\hline Post-test of reading & 30.000 & 2.97113 & 26.333 & 1.94641 & 3.667 & 5.695 & .000 \\
\hline Pre-test of writing & 9.4000 & 1.27577 & 9.0000 & 1.25945 & 0.4000 & 1.222 & .227 \\
\hline Post-test of writing & 11.4667 & 1.19578 & 10.0333 & 1.32570 & 1.43333 & 4.397 & .000 \\
\hline
\end{tabular}

In the pre-test, The $\mathrm{P}$ values of the two groups in listening, reading and writing are $0.329,0.313,0.227$ respectively, all of which are greater than 0.05 , indicating that there is no significant difference between the two groups in the pretest of listening, reading and writing. In the post-test, The $\mathrm{P}$ values are 0.002, 0.000 and 0.000 respectively, p<0.05, indicating that the average scores of the two groups show an upward trend in the language test after one term of study, but there were significant differences between the experimental group and the control group in terms of language competence. Therefore, it is suggested that the intensive reading course combined with the PBL teaching model can 
promote the improvement of students' language ability. Through interviews, teachers and most of the students agree that the PBL model plays a positive role in English learning. In addition to developing the habit of finding evidence on the basis of research and increasing the sense of teamwork. From activities before class and in class, students have made full use of the platform to train their language ability. the forms of language output, such as oral reports and performance, have strengthened students' phonetic correction, and indirectly have promoted the level of listening comprehension. in terms of reading skills, Students are required to do critical reading based on textbooks, and problemsolving is considered as the core to constantly stimulate them to find answers in extracurricular reading. In terms of writing, high-quality oral reports come from high-quality written output. Classroom presentations in each unit give them plenty of opportunities to write, thereby helping students to activate their reserves of vocabulary and grammar, and to constantly revise and improve their ability to make sentences and form discourses. A large number of exercises over time have reduced students' fear of English learning and have gradually formed the habit of expressing in English. Therefore, in the PBL teaching model, the students' language ability has been comprehensively improved.

\section{CONCLUSION}

The research indicates that PBL teaching model can promote the development of students' critical thinking ability and improve their second language acquisition ability compared with the traditional teaching, so that students can autonomously construct the new knowledge while achieving the development of the ability at the same time. But the experiment has also faced with unprecedented challenges, it is fundamental to the success of the experiment that teachers can actively and effectively change students from traditional passive knowledge receivers to active knowledge builders. The systematic and strict examination system is the guarantee of the experiment. The evaluation standard of critical thinking ability is the main criteria to examine the students' learning achievement. Some students have not fully adapted to the new learning model because of the short period of the experiment. Therefore, the development of some critical thinking ability and disposition requires a longer period in research and teaching practice. In addition, the limitations of measuring tools have also led to the inability of the experimental data to fully reflect the development of the subjects' abilities. Therefore, a variety of evaluation and testing methods should be applied in future research.

\section{ACKNOWLEDGEMENTS}

The research in this paper was supported by Tianjin Municipal Education Commission "the 13th 5-Year" Planning Project: Research on the Assessment Standards of Teachers' Professional Developments in Higher Institutions (NO. HE1003)

\section{REFERENCES}

[1] Albanese, M. A \& S. Mitchell. (2009). Problem-based learning: A review of literature on its outcomes and implementation issues. Academic Medicine 68.1, 52-81.

[2] Boud, D. J \& G. Feletti. (1997). The Challenge of Problem-based Learning. London: Kogan-Page.

[3] Burris, S \& B. L. Garton. (2007). Effect of instructional strategy on critical thinking and content knowledge: Using problembased learning in the secondary classroom. Journal of Agricultural Education.48.2, 106-116.

[4] Dochy, F, et al. (2003). Effects of problem-based learning: A meta-analysis. Learning and Instruction.13. 5, 533-568.

[5] Facione, P. (1992). The California Critical Thinking Disposition Inventory.CA: The California Academic press.

[6] Facione, P \& C. A Gittens. (2013). Think Critically [Z/OL] [2013.06.09]. http://wps.Pearsoncustom.com/wps/media/objects/14127/14466175/HUM180_Ch03.pdf.

[7] Nelson, E. T. (2008). Effects of Online Problem-based Learning on Teachers' Technology Integration Perceptions and Planning. Retrieved from ProQuest Digital Dissertations.AAT 3290657.

[8] Payne, E \& L. Whittaker. (2006). Developing Essential Study Skills. Harlow. England: Pearson Education Limited.

[9] Tiwari, A, et al. (2012). A comparison of the effects of problem-based learning and lecturing on the development of students' critical thinking. Medical Education. 40. 6, 547-554.

[10] Tiwari, A, et al. (1999). Enhancing students' critical thinking through problem-based learning. Marsh. Implementing Problem Based Learning Project: Proceedings of the First Asia Pacific Conference on Problem Based Learning. Hong Kong: The University Grants Committee of HongKong, Teaching Development Project. 75-86.

[11] Wen Qiufang, etc. (2009). The theoretical framework for the construction of foreign language students' speculative ability measuring tools in China. Foreign Language World 46.1, 37-43.

[12] Zhao Fei, Zou Weicheng. (2015). The theoretical Construction of interaction hypothesis: meaning, dilemma and solutions. Foreign language Teaching Theory and Practice 68.2, 78-86.

[13] Zhi Yongbi. (2014). Application of PBL in foreign language education in China. Foreign language and Foreign language Teaching 83,7. 33-37.

Jinzhu Zhang, Male, lecturer at School of Foreign Languages of Tianjin Polytechnic University, Tianjin, China. His research interest lies in the Applied Linguistics and Language Testing Theory \& Practice. 
Hongquan Lin, Male, associate professor at Personnel Department of Tianjin Polytechnic University, Tianjin, China. His research interest lies in the personnel management, information management and information systems. 